\title{
Vorwort.
}

Auf Wunsch vieler Fachgenossen sind in diesem Jahrgang der Fortschritte arabische, fett gedruckte Zahlen statt der rōmischen zur Bezeichnung der Bandnummern in Anwendung gekommen.

Die „technischen Anwendungen der Elektricität" haben, weil die Ueberfüllung sich immer drückender fühlbar macht, nur noch in sofern Berücksichtigung gefunden, als sie sich in den rein wissenschaftlichen Capiteln des Werkes unterbringen liessen; diejenigen Leser, welche eingehendere Nachweise über den Gegenstand suchen, seien auf STreoker's „Fortschritte der Elektrotechnik" verwiesen, deren Erscheinen seit 1887 die besondere Behandlung der Elektrotechnik in den Fortschritten der Physik überflüssig macht. Diesem Werke sind auch die auf Dynamomaschinen und Verwandtes bezüglichen Referate Seite 812 ff. entnommen.

\section{E. Budde.}


